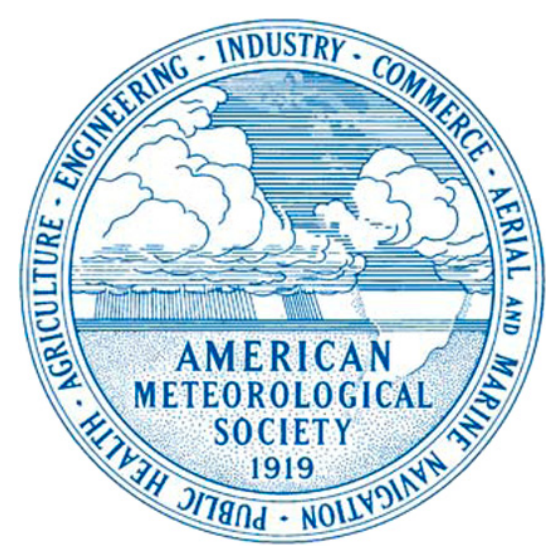

\title{
AMERICAN METEOROLOGICAL SOCIETY
}

Bulletin of the American Meteorological Society

\section{EARLY ONLINE RELEASE}

This is a preliminary PDF of the author-produced manuscript that has been peer-reviewed and accepted for publication. Since it is being posted so soon after acceptance, it has not yet been copyedited, formatted, or processed by AMS Publications. This preliminary version of the manuscript may be downloaded, distributed, and cited, but please be aware that there will be visual differences and possibly some content differences between this version and the final published version.

The DOI for this manuscript is doi: 10.1175/BAMS-D-15-00121.1

The final published version of this manuscript will replace the preliminary version at the above $\mathrm{DOI}$ once it is available.

If you would like to cite this EOR in a separate work, please use the following full citation:

Jung, T., F. Doblas-Reyes, H. Goessling, V. Guemas, C. Bitz, C. Buontempo, R. Caballero, E. Jakobson, J. Jungclaus, M. Karcher, T. Koenigk, D. Matei, J. Overland, T. Spengler, and S. Yang, 2015: Polar-lower latitude linkages and their role in weather and climate prediction. Bull. Amer. Meteor. Soc. doi:10.1175/BAMS-D-15-00121.1, in press. 


\section{Polar-lower latitude linkages and their role in weather and climate}

${ }_{3}$ Thomas Jung*, Francisco Doblas-Reyes, Helge Goessling, Virginie Guemas, Cecilia Bitz, Carlo

${ }_{4}$ Buontempo, Rodrigo Caballero, Erko Jakobson, Johann Jungclaus, Michae/Karcher, Torben

6

7
Koenigk, Daniela Matei, James Overland, Thomas Spengler, Shuting Yang

AWI, Bremerhaven, Germany

$$
\text { Francisco Doblas-Reyes }
$$

ICREA, IC3, and BSC, Barcelona, Spain

Helge Goessling

AWI, Bremerhaven, Germany

IC3, Barcelona, Spain, and CNRM, Toulouse, France

Cecilia Bitz

Carlo Buontempo

MetOffice, Exeter, UK

Rodrigo Caballero 
Meteorological Institute, Stockholm University, Stockholm, Sweden

\author{
Erko Jakobson \\ Tartu Observatory, Travere, Estonia
}

Johann Jungclaus

MPI for Meteorology, Hamburg, Germany

Michael Karcher

AWI, Bremerhaven, Germany

Torben Koenigk

SMHI, Norrkoeping, Sweden

Daniela Matei

MPI for Meteorology, Hamburg, Germany

James Overland

NOAA/PMEL, Seattle, USA

Thomas Spengler

Geophysical Institute, University of Bergen, Bergen, Norway

Shuting Yang

DMI, Copenhagen, Denmark 
${ }_{35}^{*}$ Corresponding author address: Alfred Wegener Institute, Helmholtz Centre for Polar and Marine

${ }_{36}$ Research, Bussestrasse 24, D-27570 Bremerhaven, Germany.

${ }_{37} \quad$ E-mail: Thomas.Jung@awi.de 


\section{ABSTRACT}

38 International Workshop on Polar-lower Latitude Linkages in Weather and

39 Climate Prediction

40 What: Eighty experts from twenty different countries met to assess recent

${ }_{41}$ progress in, and new directions for, our understanding of the mechanisms

42 governing polar-lower latitude linkages and their role in weather and climate

${ }_{43}$ prediction including services.

${ }_{44}$ When: 10-12 December 2014

${ }_{45}$ Where: Barcelona, Spain

46 
From 10-12 December 2014 the International workshop on Polar-lower latitude linkages and their role in weather and climate prediction was hosted by the Institut Català de Ciències del Clima (IC3) in Barcelona, Spain. The workshop, which was attended by 80 participants from 20 countries including early career scientists, was motivated by the fact that the polar regions are anticipated to undergo rapid changes in a warming world. These changes may have impacts for the weather and climate elsewhere on the planet that are not sufficiently well understood. Presentations and discussions took into account atmospheric and oceanic teleconnections in both hemispheres. A unique aspect of the Barcelona workshop was that polar-lower latitude linkages were also discussed from a prediction and services perspective. Weather and climate forecasting capacity in the polar regions is limited due to poor observational coverage and understanding of atmosphereocean-sea ice interaction, that hamper forecast quality in lower latitudes. The prediction aspect brings socio-economic relevance to the polar-lower latitude linkages theme with benefits for the development of weather and climate services.

The purpose of the workshop was to review current understanding of the workshop theme, identify known and unknown issues, define ways forward for closing important knowledge gaps, enhance cooperation,recommend specific activities for international programmes such as the Polar Prediction Project (PPP) and the Polar Climate Predictability Initiative (PCPI), and to provide research priorities for funding agencies. The workshop started by having keynote and challenger presentations; this was followed by several hours of breakout group discussions for the three different themes: (1) atmospheric linkages, (2) oceanic linkages and (3) prediction and services; finally recommendations were presented and discussed in a plenary session. Those who were not able to come to Barcelona had the opportunity to follow most of the workshop activities online. 
We provide a summary of the breakout group discussions followed by workshop recommendations. Further useful information, including the presentations, are available from the following website: http://polarprediction.net/linkages.

\section{Atmospheric linkages}

The assessment of the potential for recent Arctic changes to influence broader hemispheric weather and climate now and in the future is a difficult and controversial topic. There is little agreement on problem formulation, methods, or robust mechanisms in the research community. The best that can be said is that the science is in a pre-consensus state (Cohen et al. 2014), not unlike where ENSO research was in the late 1970s-early 1980s. The workshop was important in advancing the topic of linkages both in terms of lack of large-scale changes in seasonal climate due to Arctic amplification of temperature changes, and positive evidence for shorter term dynamic mechanisms for linkages. Despite major uncertainties due to the short observational record, given that major Arctic changes began in the early 2000s, and a large chaotic component to weather systems relative to potential Arctic forcing, the topic is significant and represents major science challenge to the international community, as continued Arctic changes are an inevitable aspect of anthropogenic global change and is an opportunity for improved extended range forecasts at midlatitudes. Advances will come from both an increased observational network and interdisciplinary understanding.

At the Barcelona workshop much discussion centered around three questions related to a possible remote impact of Arctic amplification: "Can it? Has it? Will it?" (Barnes and Screen 2015) There was general consensus that the Arctic has the potential to modify mid-latitude weather and variability; the relative importance of different possible mechanisms, however, remains to be explored. The issue "Has it?" is a continuing challenge. In this context the question why different 
people come to different conclusions from the same data was discussed. Given the magnitude of natural variability and the limited observational record, one cannot expect to be able to reject the null hypothesis that recent cold winters are due to chance, even if there were a signal; failure to reject the null hypothesis does not prove the null hypothesis. Possibly, our null (or prior) hypothesis should be anthropogenic climate change, and Arctic amplification. As a result the community at present should consider a risk-based approach to the problem formulation that increased linkages are a possibility. The issue "Will it?" is also difficult as it depends on climate models that generally lack skill in the representation of key features such as atmospheric boundary layers and, as a result, disagree in important aspects of the projected change. Further group discussion noted that there are multiple factors besides sea ice loss and snow cover which can influence atmospheric dynamics in the subarctic. A focus on surface fluxes and shifts in atmospheric dynamic patterns will provide improved insights and potential extended range forecast potential.

A main workshop conclusion is that the community must distinguish between influence on the net response and possibility of modulating the response. Hemispheric, seasonal average changes in cold surface temperatures, and dynamic features associated with them, relative to background global warming are not likely to be of large significance. However, Arctic linkages with midlatitude weather events that are regional and episodic, lead to an increased occurrence of extreme events, and vary with the season, are possible. Multiple presentations showed that linkages are likely to relate to amplification of existing regional quasi-stationary waves associated with the Siberian High and Greenland blocking locations. Complexity is added due to interaction of multiple time scales and source regions, where actual severe weather elements consist of propagation of wave trains of high/low pressure on the synoptic time scale into eastern Asia and eastern North America in early winter. 


\section{Oceanic linkages}

The science of Arctic influences on the circulation of the North Atlantic is much more mature than that for atmospheric linkages. Outflows from the Arctic Ocean at the surface and mid-depth reach the overflows and the deep-water formation sites in the sub-polar North Atlantic that feed into the meridional overturning circulation (MOC) and the sub-polar gyre (SPG) circulation. There has been consensus at the workshop that changes in the density of these outflows, for example due to freshwater or sea ice export from the Arctic or runoff from Greenland, affect the sub-polar North Atlantic in several ways: change of dense water formation in the Labrador Sea, change of the MOC strength, change of the SPG intensity. Great Salinities Anomalies observed during the second half of the 20th century are well-known examples for the Arctic-Atlantic interplay.

At the same time inflow changes of heat and salt from the sub-polar North Atlantic into the Arctic and Nordic Seas impact heat and freshwater storage of the northern basins, sea ice cover, ocean-atmosphere heat exchange and possibly even the atmospheric circulation.

It was highlighted at the workshop that both of these pathways are linked, suggesting that the Arctic-Atlantic interplay should be studied from a two-way perspective (Proshutinsky et al. 2009; Jungclaus et al. 2014). The strength of the MOC and the SPG, for example, modulate the northward heat and salt fluxes, while the Arctic Ocean freshwater storage and release dynamics regulate the sea ice and liquid freshwater exports. An important, but still largely open question is to what degree oceanic changes in the Arctic and North Atlantic impact the overlying atmosphere and hence the weather and climate over the adjacent continents, although the climate prediction community is showing convincing examples of how it can affect phenomena with societal relevance such as the frequency of tropical cyclones. 
While the existence of two-way linkages in the ocean is well established some fundamental questions still remain, especially when it comes to exploiting the full potential of oceanic linkages for predictive purposes. It will be important, for example, to better understand the pathways and time scales on which the different processes such as freshwater storage, release and advection influence the lower latitudes. Given that models will be used to carry out predictions it will be important to first thoroughly evaluate their representation of the different key processes and then advance the models where necessary. Given that successful predictions also rely on good initial conditions, poor observational coverage of the Arctic Ocean remains a key challenge. Therefore, methods will need to be devised that can be used to develop a cost effective Arctic observing system that allows to exploit the predictive potential inherent to the system. In this context, investments in the development of coupled data assimilation systems are highly desirable.

\section{Prediction and services}

Sub-seasonal prediction experiments presented at the Barcelona workshop provide evidence that what happens at the poles does not stay at the poles, especially over the Northern Hemisphere (Jung et al. 2014). On sub-seasonal time scales the Arctic impact is strongest over the eastern sections of the Northern Hemisphere continents. Furthermore, case studies for the winter 2009/10 suggested an influence of snow on the Arctic Oscillation. When it comes to prediction, snow cover, sea ice, ocean heat content and the atmosphere, including the stratosphere, are all important.

For improving forecasts, an increased understanding of how best to initialize these fields is urgently needed. This includes determining which observations are needed and how they should be assimilated. Regarding the observations, the Year of Polar Prediction (YOPP) will provide a unique opportunity to fill the gaps of the global observing system in polar regions and to use those extra data to assess and optimize the observing system. YOPP should also increase the 
quality of satellite retrieval of parameters such as snow and ice through the provision of highquality observations for calibration purposes. Given the strong coupling of the different climate components in polar regions, future data assimilation will need to be done in a coupled framework. Furthermore, substantial effort should be invested in characterizing uncertainty.

The services aspect of polar-lower latitude linkages was also discussed from a prediction perspective. It was argued that users needs should not be second-guessed and that closer interaction with users might result in the formulation of existing research questions of direct socio-economic relevance. A list of principles to interact with users of climate information has been developed and climate scientists are encouraged to use them. At the same time user needs in the Arctic are not yet fully understood, and it might be beneficial to involve mediators in establishing and guiding an efficient dialogue.

\section{Key recommendations}

- Improve understanding of the key processes in atmosphere, snow, sea ice and ocean responsible for linking the polar regions with the lower latitudes. Progress hinges on an improved observational base and on bringing expertise in high-latitude and middle-latitude dynamics together.

- Ensure that these key processes are well represented in models used to carry out weather and climate predictions. This task includes data assimilation, improved Arctic-centered model development and parameterizations, and thorough forecast assessments.

- Link the research performed for weather and climate forecasting with that carried out to project future climate to obtain the largest benefit from their synergies. This task should be planned well ahead of the CMIP6 exercise. 
- The community must distinguish between a potential Arctic influence on the net seasonal response and the possibility of regional episodic amplification of existing planetary wave patterns and related short-term weather events.

- Carry out coordinated model experiments to thoroughly assess possible remote impacts of polar climate change. Emphasis should be put on both local and possible global consequences of Arctic amplification.

- Explore the limits of predictability of polar weather and climate and their role for mid-latitude forecasting.

- Determine the impacts of enhanced predictive capacity in the polar regions for mid-latitude forecasting by carrying out coordinated forecasting experiments (e.g. data denial and relaxation experiments). Studying linkages from a sub-seasonal prediction perspective will allow better understanding of the prediction process and verification of polar-lower latitude pathways.

- Ensure that environmental prediction and model assessment requirements will have a high priority in the future development of the polar observing systems. The Year of Polar Prediction (YOPP), which will be held from mid-2017 to mid-2019, provides a unique opportunity for the international community to jointly advance our observational capacity.

- Raise the profile of Antarctic research and its impact on the Southern Hemisphere climate, especially over land.

- Create a working group to tackle the specificity of polar service provision. This working group could illustrate the benefits that stakeholders with interests at lower latitudes might have in improving polar predictions. 
- Simplify the funding process for research collaboration on an international level.

Acknowledgments. We acknowledge Francois Massonnet for reading the summary and for verifying the accuracy of the content. The report reflects ideas from a variety of workshop participants. The workshop was sponsored by the Polar Prediction Project (PPP) of WMOs World Weather Research Programme (WWRP), the World Climate Research Programme (WCRP), the Global Framework for Climate Services (GFCS), the European Commission through the Seventh Framework Programme SPECS project, the European Climate Research Alliance (ECRA), and the European Geophysical Union (EGU), as well as IC3 and the Alfred Wegener Institute Helmholtz Centre for Polar and Marine Research (AWI).

\section{References}

Barnes, E., and J. Screen, 2015: The impact of Arctic warming on the midlatitude jet-stream: Can it? Has it? Will it? WIREs Clim. Change, doi:10.1002/wcc.337.

Cohen, J., and Coauthors, 2014: Recent Arctic amplification and extreme mid-latitude weather. Nature Geosci., 7, 627-637.

Jung, T., M. Kasper, T. Semmler, and S. Serrar, 2014: Arctic influence on subseasonal midlatitude prediction. Geophys. Res. Lett., 41, 3676-3680, doi:10.1002/2014GL059961.

Jungclaus, J., K. Lohmann, and D. Zanchettin, 2014: Enhanced 20th-century heat transfer to the Arctic simulated in the context of climate variations over the last millennium. Clim. Past, 10, 2201-2213, doi:10.5194/cp-10-2201-2014.

Proshutinsky, A., and Coauthors, 2009: Beaufort Gyre freshwater reservoir: State and variability from observation. J. Geophys. Res., 114, C00A10, doi:10.1029/2008JC005 104. 